\title{
Probiotic Yogurt Formulated with Nettle (Urtica Dioica) Extract, a Compound with Dual Functionalities: Bifidobacterium Growth Promoter and Helicobacter Pylori Growth Inhibitor
}

\author{
Behzad Kanani*1, Asghar Khosrowshahi ${ }^{1}$, Mohammad Alizadeh Khaledabad ${ }^{1}$ and Rezvan Pourahmad ${ }^{2}$ \\ ${ }^{1}$ Department of Food Science and Technology, Urmia University, Iran \\ ${ }^{2}$ Department of Food Science and Technology, Islamic Azad University, Iran
}

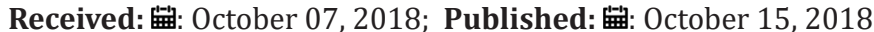

*Corresponding author: Behzad Kanani, Department of Food Science and Technology, Faculty of Agriculture, Urmia University, Urmia, Iran

\begin{abstract}
Helicobacter infection is one of the gastrointestinal diseases, which is usually treated with antibiotics and chemical medicine. These treatments suffer from antibiotic resistance. Thus, this study provides a solution using nettle (Urtica Dioica) extract along with Bifidobacterium (BF). The main challenge is transferring these two compounds to the environment containing Helicobacter pylori (H. pylori) such as stomach. The interaction between the nettle extract and BF and also with $H$. pylori were studied regarding the inhibition zone diameter, viability of probiotics, $\mathrm{pH}$ and acidity changes at three different time intervals $(1,11$, and 21 days). Results revealed that the samples containing the nettle extract showed bigger inhibition zone and consequently were more effective in preventing the growth of $H$. pylori. Furthermore, the nettle extract was enhanced the BF activity resulting in production of more antimicrobial metabolites. The alcoholic extract of nettle provided better inhibition properties than the aqueous extract. The formulated yogurts in this study could pave a new way in bringing new treatments for who suffers from Helicobacter infection induced gastrointestinal diseases.
\end{abstract}

Keywords: Bifidobacterium; Helicobacter; Probiotic; Urtica Dioica; Yogurt

\section{Introduction}

Helicobacter pylori (H. pylori) infection is a worldwide common disorder, in which up to $94 \%$ of the population in developing countries and $25-50 \%$ in developed countries are involved. $H$. pylori is known as a main cause of chronic gastritis, gastric ulcer, gastric cancer, and mucosa-associated lymphoid tissue lymphoma (MALToma) [1,2]. Treatment with antibiotics such as amoxicillin, clarithromycin, nitroimidazole, and levofloxacin) as well as bismuth and acid inhibitors (proton pump inhibitors or H2- receptor antagonist) are main procedures for overcoming this bacterium [3-5]. The main disadvantages of these types of treatments is antibiotic resistance phenomenon [6,7]. Thus, demand for finding and identifying new compounds against $H$. pylori, which can bring new therapies beside low production cost is highly appreciated by the researchers. In this regard, plant-based therapies can be one of the most common approaches. FAO and WHO introduced the probiotics as live and non-pathogenic microorganisms, which can bring more health benefits if consumed in sufficient quantities Desm006Fnd et al. [8].
Prebiotics are non-digestible substances that selectively stimulate the growth or activity of one or a limited number of bacteria in the gut Guarner et al. [9]. These compounds are regarded as the second factor to control the gut flora Crittenden et al. Products containing a combination of both probiotics and prebiotics are called a synbiotic Schrezenmeir et al. [10]. Lactobacillus and BF are the main probiotics that have more positive impact on the digestive system $[4,11]$. It was reported that these bacteria have inhibition effects on H. pillory [12-14]. Nettle herb was used in traditional medicine to treat pain and stomach ulcers Guarrera [15]. Strong antimicrobial activity of nettle extract against gram negative bacteria have been well documented Gülçin et al. [16]. A matter that distinguishes this study from other studies is gathering the three components in one product; nettle extract, Bifidobacterium (BF), and yogurt. Therefore, the effect of each parameter individually and also in combination with each other on the H. pylori was studied. 


\section{Materials and Methods}

\section{Materials}

Methanol, Brucella agar, MRS-bile agar, and Mueller Hinton Broth were purchased from Merck Chemicals (Darmstadt, Germany). Nettle leaves (Urtica Dioica) collected from West Azerbaijan region (Iran) and then approved by the botanical center of University of Urmia. Commercial yoghurt starter YC-X11 (S. thermophilus and Lactobacillus bulgaricus subspecies Delbrueckii) and probiotic bacteria BB12 (Bifidobacterium lactis) were purchased from Christian Hansen Company, Denmark, DVS. Antibiotics vancomycin, trimethoprim, and polymyxin B were purchased from SigmaAldrich (St. Louis, MO, USA).

\section{Methods}

Preparation of Nettle Extract: The nettle plant was dried and grounded (Blender/Miller III, model MS-223, Taiwan, China) and the aqueous and alcoholic extractions were carried out using nettle powder. For providing aqueous extract, $20 \mathrm{~g}$ of nettle powder were dispersed in $400 \mathrm{ml}$ hot water $\left(90^{\circ} \mathrm{C}\right)$ and were mixed using magnetic stirrer for $15 \mathrm{~min}$. The solution was then filtered using Wattman No.1 filters. The filtered solution was concentrated to the $50 \%$ under vacuum evaporator (Heidolph, Germany) Gülçin et al. [16]. For ethanolic extract, $20 \mathrm{~g}$ of nettle powder was dispersed in $20 \mathrm{ml}$ methanol $70 \%(\mathrm{v} / \mathrm{v})$ and blended then were left over night. The obtained solutions were filtered in the same previous one and were brought to $100 \mathrm{ml}$ with methanol. Finally, the extract was separated from solvent using vacuum evaporator $[17,18]$. Both extracts were placed in dark plastic bottles and were stored in a dark place at $4{ }^{\circ} \mathrm{C}$.

Preparation of Yoghurt Samples: Yogurt samples were prepared in R\&D pilot lines of Pak Corporation (Iran-Tehran) using skimmed milk (lactose 4.23\%, non-fat dry matter 7.59\%, protein content of $2.95 \%$, acidity $18 \%$, and $\mathrm{pH}$ of 6.4 ). First, the dry matter of the milk was adjusted to $11 \%$. Then, the milk was pasteurized at $85{ }^{\circ} \mathrm{C}$ for 15 minutes. After cooling to the $37{ }^{\circ} \mathrm{C}$, DVS starter and probiotic bacteria (Bifidobacterium lactis) (108 $\mathrm{cfu} / \mathrm{gr}$ ) were inoculated to the milk along with yogurt starter. In order to determine appropriate amounts of aqueous and alcoholic extracts of nettle to be added to the samples, a 5-point pre-sensory evaluations (1: the worst and 5: the best) were conducted using 20 trained panelists. Panelists were tested 1, 5, 10, 20, and 30\% of both extracts. The samples were evaluated regarding the flavor, odor, and overall acceptance. The results (data are not shown) were similar in both extracts and the samples with $10 \%$ extracts were chosen as an optimum yogurt formulation.

Thus, 10\% extracts were chosen as a standard formulation for each extract and then, concentration of $20 \%$ was chosen as a higher level of standard. The prepared yogurt formulations were as follow; control sample (probiotic yogurt, L1), probiotic yogurt containing $10 \%$ aqueous extract of nettle (L2), probiotic yoghurt containing $20 \%$ aqueous extract of nettle (L3), probiotic yoghurt containing $10 \%$ alcoholic extract of nettle (L4), and probiotic yoghurt containing 20\% alcoholic extract of nettle (L5). After addition of aqueous and alcoholic extracts of nettle at the predetermined amounts, the samples were incubated at $40{ }^{\circ} \mathrm{C}$ until the $\mathrm{pH}$ reached to the 4.6. The samples were then cooled to the $4{ }^{\circ} \mathrm{C}$ and stored 21 days at this temperature. The tests were carried out at specific time intervals $(1,11$, and 21 days).

Preparation H. pylori : Biopsy samples were gathered from patients with gastric ulcer, who were referred to the Endoscopy Center of Gastroenterology and Liver Diseases section of Shariati Hospital (Tehran-Iran). Samples were cultured on Brucella agar supplemented with 5\% defibrinated sheep blood and antibiotics vancomycin $(10 \mathrm{mg} / \mathrm{l})$, trimethoprim $(5 \mathrm{mg} / \mathrm{l})$ and polymyxin $B$ (50ug/l). After 5 days of incubation in aerobic conditions containing $10-11 \%$ of carbon dioxide, $90-100 \%$ humidity, and temperature of $37^{\circ} \mathrm{C}$, the sleek and small diameter of 1-2 ml colonies were isolated and purified. The identity of the bacteria was investigated by Gram staining, microscopic and macroscopic evaluation of morphology, and biochemical tests such as catalase, rapid urease, and oxidase Lyudmila Boyanova et al. [19].

Microbial Culturing: Bacteria suspension were prepared in Mueller Hinton Broth in accordance to the standard McFarland 2 $(6 \times 108 \mathrm{cfu} / \mathrm{ml})$. Wells with $7 \mathrm{~mm}$ diameter were created on each plate using sterile steel borer. $100 \mathrm{ul}$ of bacterial suspension was injected into the wells. Plates were then incubated for 7-5 days in microaerophilic conditions at $37^{\circ} \mathrm{C}$. The diameter of area that $H$. pylori did not grow was measured with a ruler $[20,21]$.

Probiotic Bacteria Count: Probiotic bacteria count was performed using MRS-bile (+ L-cysteine) agar medium and dilutions were conducted with peptone water. $1 \mathrm{~g}$ of yogurt samples were poured in a sterile tubes and $9 \mathrm{ml}$ sterile peptone water was added to each one and vortexed. Then, $100 \mathrm{ul}$ was added to each well. After that, the incubation was performed in anaerobic conditions at $37^{\circ} \mathrm{C}$ for 48 hours. The results were calculated using following equation and the data were reported as mean values Kailasapathy [22].

$$
c f u=c f u / \text { plate } * \quad \text { dilution factor (Eq.1) }
$$

pH Measurements: $\mathrm{pH}$ of samples was measured using Ghasempour et al, [23] method. The $\mathrm{pH}$ of $10 \mathrm{~g}$ of homogenized yogurts were measured using a $\mathrm{pH}$ meter (Eutech instrument, Singapore).

Total Titrable Acidity (TTA): 9mg of yogurt samples were mixed with $9 \mathrm{ml}$ distilled water. Then, the titration was carried out $0.1 \mathrm{~N}$ until achieving to a stable pink color in the presence of phenolphthalein. The TTA was calculated using Eq.2.

$$
T T A \%=N \times 0.009 / V \times 100
$$

Where $\mathrm{N}$ and $\mathrm{V}$ represent the normality and volume of caustic soda, respectively.

Statistical Analysis: All the experiments were conducted in triplicate and the mean values were stated. Statistical analysis was run on a completely randomized design (CRD) using one-way ANOVA and Duncan's mean comparison test at the 5\% significance level using SPSS version 18.0. The Pearson correlation coefficient was chosen to evaluate the correlation between the parameters (SPSS version 18.0). 


\section{Results and Discussion}

\section{Anti- Helicobacterial Activity}

Anti- Helicobacterial activity of the samples were analyzed using inhibition zone diameter (IZD) (Figure 1). On the first day of yogurt production, an increase in concentration of extracts had little effect on the IZD. As there was just one day after sample preparation, lower IZD can be related to the lower time for activity of probiotics and obtained IZD mainly attributed to the antimicrobial activity of nettle extracts. As shown in Figure 1, IZD was increased during 21 days of storage. This increase can be as a result of viable $\mathrm{BF}$ and production of more secondary metabolites. Thus, the data for first day are related to the direct inhibitory effect of nettle extract on the H. pillory and the results during the storage time are attributed to the effect of nettle extract on the BF activities. Extracts act as a prebiotic substance for BF and leads to more activity and production of more acidic compounds and metabolites. The differences between L3 and L5 with L2 and L4 samples indicates that the higher concentrations of extracts inhibit the bacterial activity due to the presence of too much extract in the medium. This has led to lower activity of BF, but IZD was still more than the samples with lower concentrations. According to the Figure 1, alcoholic extract showed greater impact on the IZD of H. pillory. Phenolic and antioxidant compounds are the main factors inhibiting the growth of H. pylori Chun et al. [24].

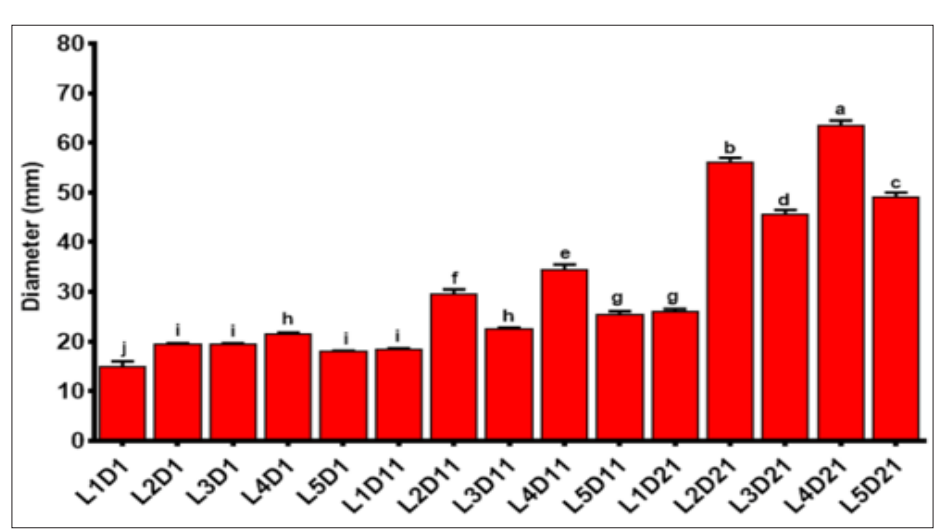

Figure 1: Anti- Helicobacterial activity of formulated yogurts. Control sample (probiotic yogurt, L1), probiotic yogurt containing $10 \%$ aqueous extract of nettle (L2), probiotic yoghurt containing 20\% aqueous extract of nettle (L3), probiotic yoghurt containing $10 \%$ alcoholic extract of nettle (L4), and probiotic yoghurt containing 20\% alcoholic extract of nettle (L5) (Different superscript letters show nonsignificant difference at the $5 \%$ level in Duncan's test, D: Day).

Therefore, by regarding this fact that the alcoholic extract is able to extract more particular phenolic and antioxidant compounds, it will have more anti-Helicobacterial activity than that of aqueous extract $[25,26]$. The nettle extract is also a phytomedicine. In this regard, possible mechanisms include $H$. pylori urease inhibition, disruption of bacterial cell membranes and modulation of the host immune system Vítor et al. [27]. The anti-bacterial, anti-oxidant, and anti-injured effects of nettle were investigated as well as identifying its phenolic compounds, compounds with antioxidant activity, and other compounds with antibacterial activity against bacterial. The analytical methods such as high-performance liquid chromatography (HPLC) and gas chromatography (GC) were indicated that the leaves of nettle are potent places for phenolic compounds Guarrera et al. [25,28-31]. The results were in good match with others. Fermented milk is effective on $H$. pylori infection and gastrointestinal tract along with BF Miki et al. [32]. There was a report about inhibition effect of 6 BF with the IZD of 8-18 mm Collado et al. [33]. One of the mechanisms that the probiotic yogurts can affect the growth of H. pillory, are the hydrogen (as an energy source for H. pillory) neutralizing capability of BF in the stomach Olson et al. [34].

\section{Bifidobacteria Count Evaluations}

BF counts were indicated in Figure 2. At first day of production, all samples were significantly different from each other $(p<0.05)$.
The highest and lowest counts were obtained for L4 and L2 samples, respectively. On the $11^{\text {th }}$ day, there is a decrease trend in bacterial counts. In general, a downward trend in the population of BF was observed during storage time. This decrease was more intense on $11^{\text {th }}$ day, which can be mainly attributed to the lower $\mathrm{pH}$ values. The $\mathrm{pH}$ of 4.5 is a critical point for survival of BF. Although the control sample had the lowest counts, it still has a normal range of BF population. It is thought that the nettle extract had positive effects on the viability of BF. This results proved the prebiotic activity of nettle extract. In order to avoid reduction in the number of $\mathrm{BF} \mathrm{pH}$ values should not become less than 4.5 during storage time. But, it is an inevitable occurrence during yogurt storage.

Thus, it was considered that a portion of the BF will be lost during storage time. The reduction in $\mathrm{pH}$ values was the main reason for BF counts Donkor et al. [35]. Several studies have been reported that the survival of $\mathrm{BF}$ is often low in yogurt medium Illupapalayam et al. [36]. Figure 2 showed that the ability of probiotic bacteria (BF) to extend the shelf life can be decreased due to the reduction of nutrients and $\mathrm{pH}$ of environment. But the number of viable probiotics was in the standard range to produce a probiotic yogurt. Viability of probiotics in yogurt during storage until is very important and at the time of intake there should be at least 105-106 $\mathrm{cfu} / \mathrm{g}$ or $\mathrm{cfu} / \mathrm{ml}$ in order to achieve useful therapeutic effects Cruz et al. [37]. The samples containing higher extract concentrations 
(L3 and L5) showed less BF population than the sample with the less positive impact of nettle extract on the viability of BF when lower extract concentration (L2 and L4). These results indicate a applied in high concentrations.

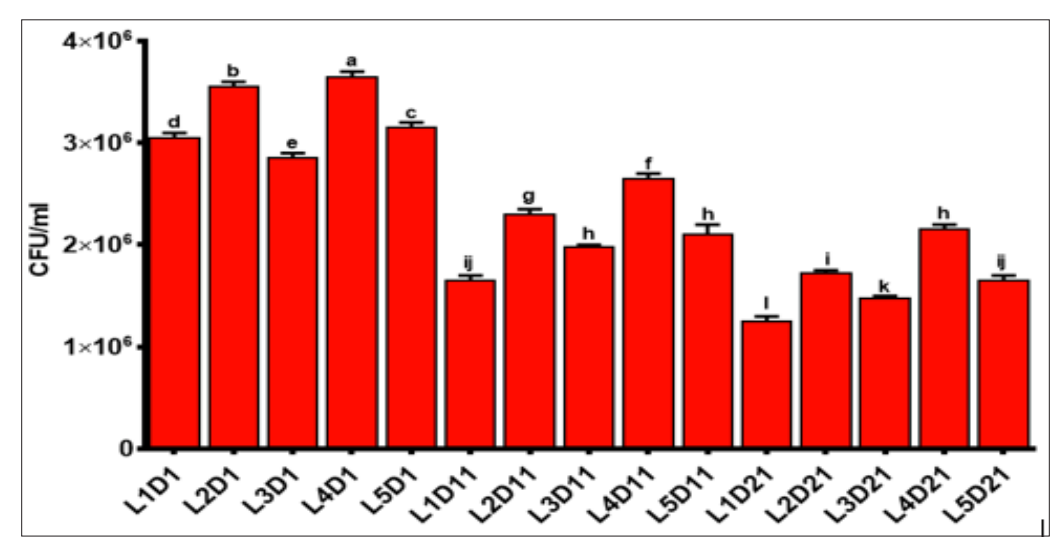

Figure 2: Bifidobacteria count evaluations in formulated yogurts. Control sample (probiotic yogurt, L1), probiotic yogurt containing 10\% aqueous extract of nettle (L2), probiotic yoghurt containing $20 \%$ aqueous extract of nettle (L3), probiotic yoghurt containing $10 \%$ alcoholic extract of nettle (L4), and probiotic yoghurt containing 20\% alcoholic extract of nettle (L5) (Different superscript letters show nonsignificant difference at the $5 \%$ level in Duncan's test, D: Day).

\section{pH Evaluations}

The $\mathrm{pH}$ analysis of the samples was reported in Figure 3. On the first day of production, the $\mathrm{pH}$ values of yogurt samples were at normal range $(\mathrm{pH}=4.6)$. On the 11th and 21st day after production, the $\mathrm{pH}$ values were significantly reduced ( $\mathrm{p}<0.05)$. In general, the $\mathrm{pH}$ values were decreased during all the storage time. These results are consistent with other findings Amirdivani et al. [38]. The pH decrease is mainly due to activity of acid-producing bacteria. However, it should be noted that the acetate produced by $\mathrm{BF}$ prevent further reducing in the $\mathrm{pH}$ values. As shown in Figure 3, the decrease in $\mathrm{pH}$ values were occurred more intensive in extract containing samples, which is due to the increase in BF activity. These finding were in a good match with others Singh $[39,40]$. Nettle extract acts like a prebiotic substrate and increased activity of the BF. The L2 and L4 samples showed lower $\mathrm{pH}$ values indicating that the highest concentrations of nettle extract provide lower positive effects on the activity of BF.

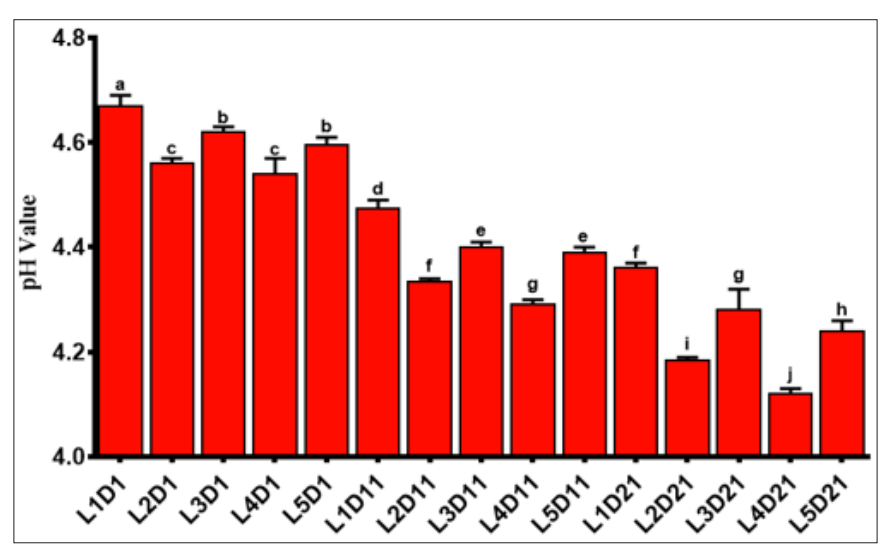

Figure 3: pH evaluations of formulated yogurts. Control sample (probiotic yogurt, L1), probiotic yogurt containing 10\% aqueous extract of nettle (L2), probiotic yoghurt containing 20\% aqueous extract of nettle (L3), probiotic yoghurt containing 10\% alcoholic extract of nettle (L4), and probiotic yoghurt containing 20\% alcoholic extract of nettle (L5) (Different superscript letters show nonsignificant difference at the $5 \%$ level in Duncan's test, D: Day).

\section{Total Titrable Acidity (TTA)}

The data for TTA\% was presented in Figure 4. At first day, results showed similar acidity in samples containing extracts with no significant differences ( $p>0.05$ ), while lower acidity in the control sample was observed. At day of 11 and 21, the highest and lowest acidity of the samples were attributed to the L4 and L3, respectively. Acidity has maintained a rising trend during 21 days of storage and this trend was more intense at 11th day of storage. During the storage time, the lowest acidity was related to the control sample. This shows that, the extracts provide an appropriate environment for BF consequently increase the acidity in samples containing extracts. These results were in line with other researchers Behrad, et al. [39]. It seems that nettle extract has a positive effect on the activity of BF and increased their metabolite production, which mainly produces more acidic substances. 


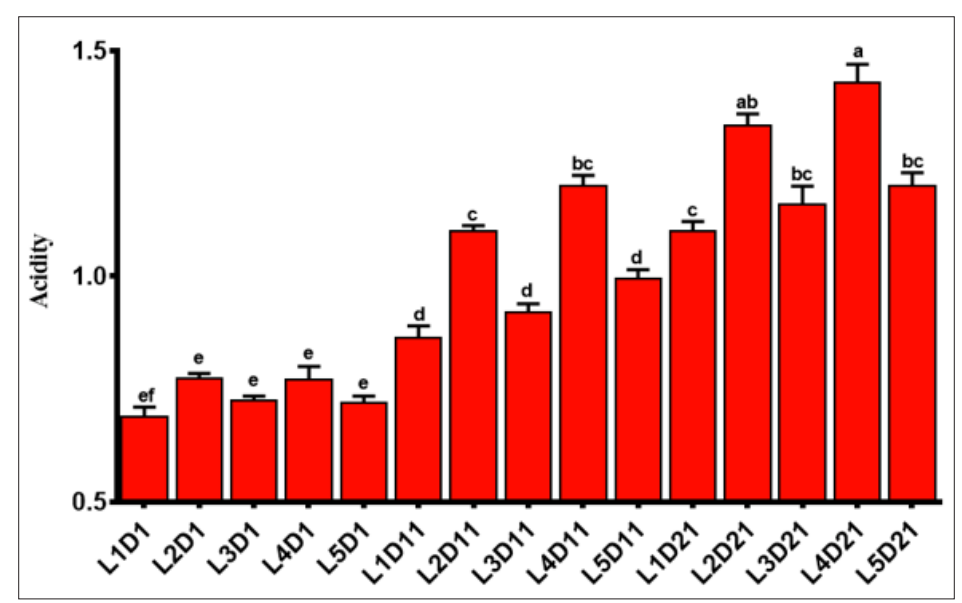

Figure 4: Total titrable acidity evaluations of formulated yogurts. Control sample (probiotic yogurt, L1), probiotic yogurt containing $10 \%$ aqueous extract of nettle (L2), probiotic yoghurt containing 20\% aqueous extract of nettle (L3), probiotic yoghurt containing $10 \%$ alcoholic extract of nettle (L4), and probiotic yoghurt containing 20\% alcoholic extract of nettle (L5) (Different superscript letters show nonsignificant difference at the $5 \%$ level in Duncan's test, D: Day).

This thought was proved with the fact that BF can produce lactic acid and acetic acid from lactose with their fructos-6phosphate enzyme Bruno et al. [38]. The reason for low positive effects of the nettle extract on the BF is mainly attributed to more accumulation of antibacterial components derived from nettle extracts. The enhanced anti-Helicobacterial effects of the Lactobacillus bulgaricus subspecies Delbrueckii was reported at lower $\mathrm{pH}$ values L Boyanova et al. [39,40]. Streptococcus thermophilus, another yogurt starter, shows its inhibitory effects on H. pillory by producing lactic acid. This effect is weaker than that of Lactobacillus. It was reported that the standard yogurt culture and also the yogurt itself had remarkable inhibitory effects on the H. pillory by providing inhibition zone diameter of 16 and $18 \mathrm{~mm}$, respectively Chitra \& Belma.

\section{Conclusion}

The Pearson correlation test on pH-IZD, pH-Acidity, and Acidity-IZD was $-0.907,-0.874$, and -0.907 , respectively. Results showed that the $\mathrm{pH}$ and acidity are two main factors that have a significant reverse relationship with the inhibition zone diameter. It is important to note that although the increasing activity of probiotic bacteria cause a loss in the live bacterial population, the inhibited growth of $H$. pylori was mainly due to the accumulation of anti- helicobacterial compounds. Peptides in milk and milk products such as yogurt were exhibited antibacterial properties. Yogurt's antimicrobial activity against $H$. pylori infection can be attributed to its BF strains producing acid and other antimicrobial metabolites. Nettle extract showed different effects on both; inhibition of H. pylori growth and viability of BF, which totally leads to inactivity of $H$. pylori. The alcoholic extract was more efficient regarding the phytomedicine effects of nettle. Furthermore, it can act as a prebiotic compound, which can have provocative effects on the growth of BF. Finally, the results of the present study could bring new yogurt formulations in order to cure H. pylori disorder as well as the medical treatments.

\section{Acknowledgment}

This research was conducted at the University of Urmia, Urmia, Iran.

\section{References}

1. Mégraud F, Lehours P (2007) Helicobacter pylori detection and antimicrobial susceptibility testing. Clinical Microbiology Reviews 20(2): 280-322.

2. Wroblewski LE, Peek RM, Wilson KT (2010) Helicobacter pylori and gastric cancer: factors that modulate disease risk. Clinical Microbiology Reviews 23(4): 713-739.

3. Gisbert JP (2009) Review: Second-line rescue therapy of Helicobacter pylori infection. Therapeutic Advances in Gastroenterology 2(6): 331356.

4. Hamilton Miller J (2003) The role of probiotics in the treatment and prevention of Helicobacter pylori infection. International Journal of Antimicrobial Agents 22(4): 360-366.

5. Malfertheiner P, Megraud F, O'morain CA, Atherton J, Axon AT, Bazzoli F, Rokkas T (2012) Management of Helicobacter pylori infection-the Maastricht IV/Florence consensus report. Gut 66(1): 646-664.

6. Adamek R, Suerbaum S, Pfaffenbach B, Opferkuch W (1998) Primary and acquired Helicobacter pylori resistance to clarithromycin, metronidazole, and amoxicillin-influence on treatment outcome. The American Journal of Gastroenterology 93(3): 386-389.

7. Megraud F (2004) H pylori antibiotic resistance: prevalence, importance, and advances in testing. Gut 53(9): 1374-1384.

8. Desmond C, Stanton C, Fitzgerald GF, Collins K, Ross RP (2001) Environmental adaptation of probiotic lactobacilli towards improvement of performance during spray drying. International Dairy Journal. 11(10): 801-808.

9. Guarner F, Khan AG, Garisch J, Eliakim R, Gangl A, et al. (2008) World Gastroenterology Organisation Practice Guideline: Probiotics and Prebiotics-May 2008: guideline. South African Gastroenterology Review $6(2): 14-25$.

10. Schrezenmeir J, De Vrese M (2001) Probiotics, prebiotics, and synbioticsapproaching a definition. The American Journal of Clinical Nutrition 73(2): 361-364. 
11. Sullivan $\AA$, Nord C (2005) Probiotics and gastrointestinal diseases. Journal of Internal Medicine 257(1): 78-92.

12. Aiba Y, Suzuki N, Kabir AM, Takagi A, Koga Y (1998) Lactic acidmediated suppression of Helicobacter pylori by the oral administration of Lactobacillus salivarius as a probiotic in a gnotobiotic murine model. The American Journal of Gastroenterology 93: 2097-2101.

13. Enany S, Abdalla S (2015) In vitro antagonistic activity of Lactobacillus casei against Helicobacter pylori. Brazilian Journal of Microbiology 46(4): 1201-1206.

14. Sgouras D, Maragkoudakis P, Petraki K, Martinez Gonzalez B, Eriotou E, et al. (2004) In vitro and in vivo inhibition of Helicobacter pylori by Lactobacillus casei strain Shirota. Applied and Environmental Microbiology 70(1): 518-526.

15. Guarrera PM (2005) Traditional phytotherapy in Central Italy (Marche, Abruzzo, and Latium). Fitoterapia 76(1): 1-25.

16. Gülçin, I, Küfrevioğlu Öİ, Oktay M, Büyükokuroğlu ME (2004) Antioxidant, antimicrobial, antiulcer and analgesic activities of nettle (Urtica dioica L.) Journal of Ethnopharmacology 90(2): 205-215.

17. Mitscher L, Leu RP, Bathala M, Wu W, Beal J (1972) Antimicrobial agents from higher plants. I. Introduction, rationale, and methodology. Lloydia 35(2): 157-166.

18. Zaidi SFH, Yamada K, Kadowaki M, Usmanghani K, Sugiyama T (2009) Bactericidal activity of medicinal plants, employed for the treatment of gastrointestinal ailments, against Helicobacter pylori. Journal of Ethnopharmacology 121(2): 286-291.

19. Boyanova L, Koumanova R, Lazarova E, Jelev C (2003) Helicobacter pylori and Helicobacter heilmannii in children. A Bulgarian study. Diagnostic Microbiology and Infectious Disease 46(4): 249-252.

20. Duck WM, Sobel J, Pruckler JM, Song Q Swerdlow D, et al. (2004) Antimicrobial resistance incidence and risk factors among Helicobacter pylori-infected persons, United States. Emerging Infectious Diseases 10(6): 1088-1094.

21. Shahani S, Monsef Esfahani HR, Saeidnia S, Saniee P, Siavoshi F, et al. (2012) Anti-Helicobacter pylori activity of the methanolic extract of Geum iranicum and its main compounds. Zeitschrift für Naturforschung C 67(3): 172-180.

22. Kailasapathy K (2006) Survival of free and encapsulated probiotic bacteria and their effect on the sensory properties of yoghurt. LWT-Food Science and Technology 39(10): 1221-1227.

23. Ghasempour Z, Alizadeh M, Bari MR (2012) Optimisation of probiotic yoghurt production containing Zedo gum. International Journal of Dairy Technology 65(1): 118-125.

24. Chun SS, Vattem DA, Lin YT, Shetty K (2005) Phenolic antioxidants from clonal oregano (Origanum vulgare) with antimicrobial activity against Helicobacter pylori. Process Biochemistry 40(2): 809-816.

25. Nencu I, Vlase L, Istudor V, Duțu LE, Gird CE (2012) Preliminary research regarding the therapeutic uses of Urtica dioica L. Note I. The polyphenols evaluation. Farmacia 60(4): 493-500.

26. Nostro A, Cellini L, Bartolomeo SD, Campli ED, Grande R, et al. (2005) Antibacterial effect of plant extracts against Helicobacter pylori. Phytotherapy Research 19(3): 198-202.
27. Vítor J, Vale FF (2011) Alternative therapies for Helicobacter pylori: probiotics and phytomedicine. Pathogens and Disease 63(2): 153-164.

28. Gulcin I, Buyukokuroglu ME, Oktay M, Kufrevioglu OI (2002) On the in vitro antioxidative properties of melatonin. Journal of Pineal Research 33(3): 167-171.

29. Lahigi SH, Amini K, Moradi P, Asaadi K (2011) Investigating the chemical composition of different parts extracts of bipod nettle Urtica dioica L. in Tonekabon region. Physiology 2(1): 337-340.

30. Miki K, Urita, Y, Ishikawa F, Iino T, Shibahara Sone H, Akahoshi R, Hirano K (2007) Effect of Bifidobacterium bifidum fermented milk on Helicobacter pylori and serum pepsinogen levels in humans. Journal of Dairy Science 90(6): 2630-2640.

31. Collado M, Gonzalez A, Gonzalez R, Hernandez M, Ferrus M, et al. (2005) Antimicrobial peptides are among the antagonistic metabolites produced by Bifidobacterium against Helicobacter pylori. International Journal of Antimicrobial Agents 25(5): 385-391.

32. Olson JW, Maier RJ (2002) Molecular hydrogen as an energy source for Helicobacter pylori. Science 298(5599): 1788-1790.

33. Donkor O, Henriksson A, Vasiljevic T, Shah N (2006) Effect of acidification on the activity of probiotics in yoghurt during cold storage. International Dairy Journal 16(10): 1181-1189.

34. Illupapalayam VV, Smith SC, Gamlath S (2014) Consumer acceptability and antioxidant potential of probiotic-yogurt with spices. LWT-Food Science and Technology 55(1): 255-262.

35. Cruz A, Castro W, Faria J, Lollo P, Amaya Farfán J, et al. (2012) Probiotic yogurts manufactured with increased glucose oxidase levels: Postacidification, proteolytic patterns, survival of probiotic microorganisms, production of organic acid and aroma compounds. Journal of Dairy Science 95(5): 2261-2269.

36. Amirdivani S, Baba AS (2011) Changes in yogurt fermentation characteristics, and antioxidant potential and in vitro inhibition of angiotensin-1 converting enzyme upon the inclusion of peppermint, dill and basil. LWT-Food Science and Technology 44: 1458-1464.

37. Behrad S, Yusof M, Goh K, Baba A (2009) Manipulation of probiotics fermentation of yogurt by cinnamon and licorice: effects on yogurt formation and inhibition of Helicobacter pylori growth in vitro. World academy of Science Engineering and Technology 60: 590-594.

38. Bruno F, Lankaputhra W, Shah N (2002) Growth, viability and activity of Bifidobacterium spp. in skim milk containing prebiotics. Journal of Food Science 67(7): 2740-2744.

39. Boyanova L, Stephanova Kondratenko M, Mitov I (2009) AntiHelicobacter pylori activity of Lactobacillus delbrueckii subsp. bulgaricus strains: preliminary report. Letters in Applied Microbiology 48(5): 579-584.

40. Crittenden R, Bird A, Gopal P, Henriksson A, Lee Y (2005) Probiotic research in Australia, New Zealand and the Asia-Pacific region. Current Pharmaceutical Design 11(1): 37-53. 
ISSN: 2574-1241

DOI: $10.26717 /$ BJSTR.2018.10.001888

Behzad Kanani. Biomed J Sci \& Tech Res

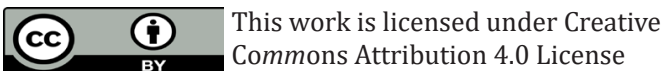

Submission Link: https://biomedres.us/submit-manuscript.php

$\begin{array}{ll}\text { BIOMEDICAL } & \text { Assets of Publishing with us } \\ \text { RESEARCHES } & \text { - Global archiving of articles } \\ \text { - Immediate, unrestricted online access } & \text { - Rigorous Peer Review Process } \\ & \text { - Authors Retain Copyrights }\end{array}$

